\title{
O EXCESSO BATAILLEANO COMO FATOR DE COERÊNCIA ENTRE PROCESSOS: UMA HIPÓTESE DE RESPOSTA AO OBJETIVO WHITEHEADIANO À FILOSOFIA DA CIÊNCIA
}

\author{
BATAILLEAN EXCESS AS A FACTOR OF COHERENCE BETWEEN \\ PROCESSES: A HYPOTHESIS TO ANSWER THE WHITEHEADIAN PURPOSE \\ TO PHILOSOPHY OF SCIENCE
}

\author{
Rafael Ferreira Martins ${ }^{1}$
}

\begin{abstract}
RESUMO: Este artigo apresenta uma resposta ao propósito de Whitehead à filosofia da ciência, buscar por um relato de coerência entre eventos. A hipótese levantada foi a de que o conceito de Excesso, conforme apresentado por George Bataille em A Parte Maldita, pode ser um excelente recurso para relatar a coerência entre os eventos no Universo. Para corroborar tal hipótese, desenvolve-se cientificamente o conceito batailleano escolhido e, por fim, aplicao a processos discriminados na natureza, a fim de testar se é possível encontrar o Excesso como um processo essencial neles e no conjunto deles. Dados os casos estudados nesta pesquisa, conclui-se que o Excesso pode ser um fator para relatar a coerência entre séries de eventos (processos) distintos.
\end{abstract}

Palavras-chave. Whitehead. Bataille. Energia. Processo. Continuidade.

ABSTRACT: This paper presents an answer to Whitehead's philosophy of science purpose: a report of coherence between events. The raised hypothesis was that the concept of Excess, as presented by George Bataille in The Accursed Share, can be an excellent resource for reporting the coherence between events in the Universe. To corroborate this hypothesis, the chosen Bataillean concept has been scientifically developed and, finally, applied to discriminated processes in nature, in order to test if is possible to find Excess as an essential process singly and jointly at the events. By the cases studied in this research, it is concluded that the Excess can be a factor to report the coherence between distinct series of events (processes).

Keywords. Whitehead. Bataille. Energy. Process. Continuity.

\section{INTRODUÇÃO}

Em O Conceito de Natureza, o filósofo e matemático Alfred North Whitehead diferencia os objetivos da metafísica e da filosofia da ciência. Para Whitehead (1993, p. 37) o objetivo da filosofia da ciência é relatar a coerência das coisas conhecidas através da percepção,

\footnotetext{
${ }^{1}$ Formado em Física (licenciatura) pela Universidade Paulista e formando em Filosofia (bacharelado) pela Universidade de Brasília. Membro do grupo de pesquisa 'Pensamento Processual e Estudos Whiteheadianos na América Latina' (UFRJ/CNPq) e integrante do projeto de pesquisa 'Whitehead e a Point-Free Geometry' (UnB). Agraciado com Menção Honrosa e indicado ao Prêmio Destaque de Iniciação Científica no XXV CIC UnB/DF. E-mail: rafaelferreiramartins98@gmail.com.
} 
enquanto à metafísica cabe a discussão de como sintetizar o conhecedor e o conhecido em uma única realidade (WHITEHEAD, 1993, p. 36).

Dada a fundamental distinção realizada no parágrafo anterior, este artigo pode focar no ramo da filosofia da ciência sem o erro de "jornadear para além de entidades reveladas na apreensão sensível” (WHITEHEAD, 1993, p. 35), ou seja, é possível ter a clareza de que esta pesquisa trabalha com o que é conhecido sobre o Universo, não com os debates sobre como é possível, ou se é possível, conhecer o Universo.

Para Whitehead (1993, p. 20) tais 'entidades reveladas à apreensão sensível' são eventos, isto é, a ocorrência da natureza em sua totalidade. Partindo da totalidade do fato percebido, discriminamos eventos parciais, a fim de empreender um relato acerca da parcela do todo sobre a qual estamos cônscios naquele momento (WHITEHEAD, 1993, 2I).

Cada evento, para Whitehead (1993, p. 97), é composto por infinitos outros eventos e, também, compõe uma infinidade de eventos, desta forma, não há evento mínimo, nem evento máximo, na natureza. Sendo assim, para tentar realizar o relato de coerência dos eventos, a filosofia da ciência precisa prezar por elementos/fatores que não pretendam ser englobadores universais nem partículas basilares universalizantes. Atendendo aos entendimentos whiteheadianos, este trabalho considerará uma série de eventos discriminada como um processo natural.

Como hipótese de candidato ao relato da coerência entre os eventos, este artigo apresenta o conceito de Excesso, conforme exposto por George Bataille em sua obra A Parte Maldita. Especificando o Excesso em seu efeito de percurso do excedente energético, esta pesquisa aposta na potencialidade deste conceito para relatar a coerência dos eventos, consequentemente, em um Universo processual e contínuo. Processual, pois os eventos se ligam fundamentalmente por um mesmo processo, e continuo, uma vez que o mesmo elemento é essencial na internalidade dos eventos e em suas ligações.

\section{Conceituando e desenvolvendo cientificamente o Excesso de Bataille}

Para conceituar o Excesso batailleano é necessário, essencialmente, identificar do que se trata tal excesso, qual sua natureza e quais entes ele relaciona para si, seja como origem, finalidade ou intermédio. Desta maneira, este tópico discorre sobre três problemas: "excesso de quê?”, “excesso em/por quem?” e "como existe/opera o excesso?”. Para tal teremos de 
explorar questões físicas que vão além da tese de Bataille e aprofundar o conceito de Excesso cientificamente além de seu autor original.

Organismos vivos dispõem de recursos energéticos que superam seu próprio consumo mínimo, isto é, de manutenção das operações que suportam sua própria vida (BATAILLE, 2016, p. 49). Se tais recursos energéticos, isto é, pacotes de energia, puderem ser simplesmente armazenados, tal superioridade do valor de energia frente ao valor de consumo do organismo não se mostra como um problema.

A definição geral das ciências físicas para Energia como, especificamente, capacidade de realizar trabalho (GASPAR, 2005) indica-nos que, possuir recursos energéticos em excesso é possuir capacidade de trabalhar em excesso, isto é, de alterar o estado de algo; logo, organismos, como detentores de mais recurso que gasto energético, são capacitados a alterar o estado de sua realidade.

Porém, tal capacidade excessiva não pode ser retida, simplesmente armazenada em pacotes de energia, num processo cumulativo ad aeternum, ao menos - à primeira vista - não em organismos vivos, pois o próprio princípio da matéria viva exige que o excesso de um organismo seja dispendido de maneira a ser beneficiária, neste caso, ser criador de novos excedentes. Originou-se, então, uma questão: não podendo, pelo princípio da matéria viva, um organismo, simplesmente acumular infinitamente seu excesso de recursos, sua capacidade maior que necessidade, qual o destino de tal excedente?

O destino mais imediato que a capacidade orgânica dá ao seu excesso de recursos é o crescimento do organismo, uma vez que é uma realização interna a ele próprio, isto é, fundamentalmente individual, logo, mais direta possível. No exemplo de um animal doméstico que é bem alimentado, mas, artificialmente mantido em cárcere, notamos que este altera seu estado por meio da engorda, isto é, cresce ${ }^{3}$.

O destino secundário que a capacidade orgânica dá ao seu excesso de recursos é o aumento da atividade funcional. Se o excedente energético não foi consumido pelo indivíduo em si (crescimento), deve o ser pelo indivíduo no meio, isto é, pelo aumento de seu consumo

\footnotetext{
${ }^{2}$ Nomenclatura utilizada por Bataille em A Parte Maldita (2016. Tradução de J. C. Guimarães) no capítulo II da Introdução Teórica para estabelecer um axioma para os sistemas vivos: todo organismo é fruto de dispêndio de energia e lança seu excedente de maneira, parcialmente, beneficente.

${ }^{3}$ Exemplo do Bezerro doméstico, empregado por Bateille em A Parte Maldita, capítulo II, Primeira Parte.
} 
energético em sua realização para com seu meio ambiente. No exemplo animal, com um bezerro, podemos colocar o macho como tornando-se turbulento e a fêmea implementando a produção de leite (BATAILLE, 2016, p. 49). Na turbulência o macho consome mais energia que na passividade, dispendendo, com o aumento do uso muscular, o excedente de recursos energéticos; na produção de leite a fêmea consome sua energia excedente, despendendo-a no processo biológico de geração do material do leite e, ainda, despende material de caráter excessivo (visto que não é parte da manutenção mínima), mesmo que adquirido para tal finalidade, propriamente - no/o leite.

Antes de passar ao terceiro destino possível para o excedente, no caso de o primeiro e o segundo não serem suficientes, é interessante notar que o desenvolvimento até aqui já nos permite concluir do que é o Excesso. O Excesso é essencialmente de Energia (como visto no estabelecimento inicial do problema, com a proposição de que organismos vivos dispõem de recursos energéticos que superam seu próprio consumo para manutenção da vida), porém como é apresentado no segundo destino possível para consumo do excedente (aumento da atividade funcional) pela produção de leite - o Excesso não é unicamente de Energia, ou, ao menos, não pode ser distribuído, em todos os casos, simplesmente como Energia. O exemplo

da bezerra que produz leite como consumo de excedente energético nos aponta a necessidade, neste caso exemplar, do uso de material (o leite neste caso) para dar meio de despender a Energia.

Adentrando um pouco mais na dependência material do dispêndio do excedente energético (no objetivo de identificar melhor o Excesso), deve-se pontuar que a transmissão de energia (seja por excedente ou não) está intimamente associada a movimentação de matéria. Vejamos as energias térmica e química, como exemplo de tal dependência material, visto que os exemplos e o iniciar do texto referiram-se a sistemas vivos e tais energias são intimamente ligadas a esta parcela do cosmos.

A energia térmica (calor) possui três maneiras de realizar-se: irradiação, condução e convecção; destas três, somente a irradiação está completamente desprovida de material em sua ocorrência, visto que transcorre por ondas eletromagnéticas (HEWITT, 2009, cap.9). A energia química, no que lhe concerne, é uma energia potencial acumulada pelas ligações químicas dos átomos e, assim, é especificamente material, uma vez que é portada no material, nos átomos ligados. Assim, mesmo energias facilmente relacionáveis com a vida ocorrem 
majoritariamente tendo a matéria como meio, como no caso da energia química, ou como intermeio, como no caso da convecção. Ainda, vale constar, mesmo no calor ocorrido por irradiação de ondas eletromagnéticas (imaterialmente), o próprio conceito de calor evoca o material (substância) como início e fim do processo de físico do calor.

Enfim, pode-se alegar que o Excesso que buscamos é essencialmente energético, porém, ocorre, em variadas situações, tendo a matéria (esteja ela em excesso ou não) como meio ou intermeio. O exemplo do calor mostra-se útil como explanador desta conclusão, visto que o calor ocorre de uma substância para outra, isto é, tem caráter inicial e final material, porém, ocorre pela da passagem de energia de uma substância para outra, seja por meio da matéria (caso da condução), por intermeio da matéria (caso da convecção) ou em ausência de matéria (irradiação) e tem origem na diferença de energia (energia térmica) entre as substâncias, somente se concluindo pela equalização da energia entre elas. Ou seja, o dispêndio do excedente tem origem energética, início material, ocorrência material-energeticamente ou energeticamente pura, fim material e conclusão energética.

Agora, tendo compreendido melhor o que é o Excesso, pela clareza e distinção de seu caráter energético (essencialista) e material (instrumentalista), passemos para o terceiro destino possível para o excedente, no caso de o primeiro e o segundo não serem suficientes: a reprodução.

O primeiro destino de dispêndio do excedente, o crescimento, referiu-se ao organismo (portador do excesso) em/por si, isto é, como ente único e suficiente do processo; o segundo destino de dispêndio do excedente, o aumento da atividade funcional, referiu-se ao organismo (portador do excesso) e seu meio, ou seja, como ente único e dependente; o terceiro destino, por sua vez, o da reprodução, referir-se-á ao organismo em função de outro, isto é, como ente social e insuficiente.

Relacionando este terceiro destino (reprodução) com o primeiro (crescimento próprio) é correto afirmar que "reprodução significa, em certo sentido, uma passagem do crescimento individual ao de um grupo" (BATAILLE, 2016, p.49). A reprodução é a finalidade orgânica do excedente de energia que justifica o princípio da matéria viva, visto que este clama por geração de novos excedentes e a geração de um novo organismo (tendo em mente que todo organismo possui mais energia do que consome - conforme precitado) é exatamente a criação de um novo operador e detentor de excedentes energéticos. 
Porém, é possível, e até mesmo válido, levantar uma crítica ao pensamento de Bataille no que tange a necessidade de tal terceira via (da necessidade da reprodução), no raciocínio implementado para cunhar os destinos do excedente em ordem, que é o do não consumo obrigar o organismo a gerar um destino posterior de consumo. Tal crítica é válida, pois seria possível, dentro unicamente do apresentado por Bataille (em A Parte Maldita), de supor que: ainda que a via primária de dispêndio (crescimento) não possa acumular o excedente eternamente, por uma questão de limitação espacial e biológica, a via secundária (aumento da atividade funcional) não teria tais limitações, visto que o portador do excesso poderia elevar inúmeras vezes e por enormes intervalos de tempos seu consumo por atividade - o que é plausível pelo texto de Bataille, uma vez que não fica argumentada uma limitação universal para tal segundo destino.

Bataille pré-defende-se de tal crítica como em sentido de uma possibilidade de proposição universal ao falar das plantas, visto que estas são "inteiramente crescimento e reprodução (a energia necessária a sua atividade funcional é ínfima)” (BATAILLE, 2or6, P. 5o) e, assim, não poderiam, por sua natureza operacional do excedente, dado sua funcionalibilidade vegetal, acrescer a capacidade de consumo por aumento da atividade funcional enormemente, em verdade, nem minimamente.

A saída pelo pré-contra-argumento das plantas é, porém, parcial, pois não refuta a crítica, somente impossibilita que a proposição dela seja universalizável. Assim, é preciso recorrer a outro autor para fundamentar a necessidade de reprodução como saída ao excedente, para tal, abordaremos os pensamentos de Richard Dawkins, especificamente o do Gene Egoísta.

É evidente que, observando-se a parcela viva do ecossistema terrestre, a reprodução pulsa por toda parte, pois se a "superfície do globo, em princípio, é assediada pela vida na medida do possível" (BATAILLE, 2016, p. 5I) a reprodução de tal vida é fundamento para, tal assédio espacial. A pergunta, todavia, do porquê desta obsessão das formas de vida pela reprodução como meio de assédio do espaço, em detrimento de tantas outras possíveis, continua.

Segundo Richard Dawkins tal necessidade natural pela reprodução pode ser explicada não ao olhar para o organismo que reproduz, mas, sim, em menor escala, para o código genético que este dá continuidade durante a reprodução. Se pensamos o percurso do sistema biológico 
como tendo por fim o próprio organismo em busca de sua manutenção simples, viver, não conseguimos encontrar o porquê de tal direcionamento biológico para a reprodutividade, visto que, por obviedade podemos supor que: se o macroprocesso biológico fosse centrado no organismo individual, outra atividade surgiria, que não o esforço reprodutor tão energeticamente caro ao próprio indivíduo. Nota-se que Bataille preocupa-se com tal tema ao classificar a manducação, a morte e a reprodução sexuada como produtos do excedente energético (BATAILLE, 2016, p. 53) que percorre o campo biológico do globo terrestre; porém, a questão não é resolvida, ainda, aí, visto que o direcionamento biológico por reprodução supera a reprodução sexuada, alcançado a reprodução assexuada.

Se, porém, pensamos os seres vivos como "máquinas de sobrevivência - veículos robô programados cegamente para preservar as moléculas egoístas conhecidas como genes" (DAWKINS, 2007, p. I), tal qual defende Dawkins em O Gene Egoísta, podemos justificar a reprodução como via necessária na ordem dos destinos de excedente energético batailleanos, pois a continuidade de um gene é diretamente dependente da reprodução que o retransmite; logo, refuta-se a crítica imposta da possibilidade de sua não-necessidade; haja vista que o direcionamento dos seres vivos por reprodução é parte de sua natureza própria, por serem seres portadores de genes (segundo Dawkins), tal qual o excedente de recursos energéticos faz parte de sua natureza, como portadores de excedente (segundo Bataille).

Finalmente, explanou-se às três questões iniciais deste tópico, como resumido abaixo:

- Excesso de quê? Excesso de energia, que aparece como excedente por restar como diferença entre o quanto o ente detém e o quanto ele consome.

- Excesso em/por quem? Todo ser que possui uma capacidade de realizar trabalho superior ao seu próprio trabalho para manutenção em vida - os organismos vivos, por exemplo, assim são (todos) por natureza. Nenhum ente detém indefinidamente seu excedente, mas, pelo contrário, lança-o forçadamente adiante no ambiente.

- Como existe/opera o excesso? Tem origem energética, início material, ocorrência material-energética ou energética pura, fim material e conclusão energética; ou seja, tem por essência a energia e, pode ter, por instrumento a matéria. O excesso é, necessariamente, caminhante, pois não podendo ser detido indefinidamente por nenhum ente e tendo caráter essencialmente energético é, então, dinâmico, ou melhor explicando, no caso da vida, é parte fundamental da dinâmica dos seres. 


\subsection{Verificando o Excesso em séries de eventos (processos) distintos}

Neste tópico, a ocorrência do Excesso ou, especificamente, o percurso do excedente energético, será verificado em duas séries de eventos discrimináveis, isto é, processos, de dimensões cósmicas distintas (astronômica e biológica) para verificar se podem ser considerados como ligados através de um mesmo processo mais amplo e, ainda, se este processo é internamente essencial em ambos - sendo tal processo amplo o percurso do excedente energético através dos processos discriminados.

Bataille apresenta, em A Parte Maldita, que toda a energia que está em excesso na biosfera terrestre é resultado da energia enviada gratuita e continuamente pelo sol através da luz que emite. A relação entre a estrela sol e o planeta Terra é de nível astronômico, utilizemola, então, como exemplo de caso de nível astronômico para verificar a evidência do percurso do excesso nela.

Para validar a emissão de luz (energia luminosa) do sol como evidência, corroborando o percurso do excesso na natureza, é necessário averiguar se o processo que engloba tal emissão é: (I) iniciado por um excesso energético, (2) mediado pela liberação do excedente de energia e (3) finalizado na recepção, por outro processo, da respectiva energia liberada (conforme explicado e descrito no tópico 2 deste artigo). Se estas 3 etapas forem comprovadas, pode-se, por conseguinte lógico, declarar o nível astronômico como evidenciando positivamente o percurso do excesso na natureza.

Para compreender, com pleno rigor científico, as 3 etapas no processo de emissão de luz (energia luminosa) do sol, recorre-se ao texto What Makes The Sun Shine (em tradução direta ao português: "O que faz o sol brilhar?”) do serviço de divulgação científica StarChild, do Arquivo do Centro de Pesquisa de Altas Energias e Ciências Astrofísicas da NASA, que fornece as explanações necessárias, vide citação a seguir (traduzida pelo autor deste artigo).

Nosso sol providencia uma quantidade essencial e constante de calor e luz para a Terra nos últimos 4.5 bilhões de anos. Mas o que justamente gerou essa energia por tão longo período? [...] O calor e a pressão no núcleo, ou centro, do sol são tão elevados que prótons podem se chocar uns com os outros com força suficiente para se unirem. Se 4 prótons são esmagados em união, o resultado é: dois prótons e dois nêutrons [núcleo de Hélio], dois pósitrons e alguma energia. [...] Por que a energia extra? Einstein nos mostrou que $E=m \cdot c^{\wedge} 2$, o que nos diz que, qualquer perda de massa $(m)$ resulta no aparecimento de energia (E). c é a velocidade da luz e é igual a $300.000 \mathrm{~km} / \mathrm{s}$ [valor que, conforme a equação, intermédia, multiplicando, a 
passando da massa para energia]. Um núcleo de Hélio é somente 99,3\% tão pesado quanto 4 prótons. A massa perdida é convertida em energia. É essa energia que causa o brilho da estrela e impede seu colapso [...]. (TRUELOVE \& DEJOIE, i999, p. I)

Com isso, é possível responder às 3 etapas de comprovação: (I) a emissão de luz solar tem, de fato, origem em um excesso energético - a transformação de massa em "energia extra" após a formação do núcleo de Hélio; (2) a emissão de luz solar é, efetivamente, mediação do excedente, ou seja, resolução possível para que o excesso não colapse o corpo, encontrando um meio para liberá-lo - a estrela brilha, isto é, libera a "energia extra" (excedente) por meio de luz "impedindo seu colapso"; (3) a emissão de luz solar, realmente, acaba por encontrar outro processo, como os processos biológicos e geológicos do planeta Terra, onde tal energia excedente liberada pelo sol tem "providenciado uma quantidade essencial e constante de calor e luz".

Assim, tendo, a emissão de luz solar, atendido corretamente às 3 etapas de verificação, pré-estipuladas para averiguação do percurso do excesso na natureza, e sendo tal fenômeno o exemplo aqui implementado do nível natural astronômico, infere-se a evidência do percurso do excesso ao nível astronômico. O próximo nível natural a ser verificado, seguindo as mesmas 3 etapas, é o biológico.

Diversos processos terrestres captam a energia da emissão de luz solar, nos mais diversos níveis de recorte da natureza (geológicos, meteorológicos, etc.), porém, dada a finitude deste artigo, decidiu-se pela escolha de um processo do nível biológico em detrimento dos demais, isto, considerando a centralidade de tal processo para o suporte de vida no planeta terra: a fotossíntese.

Analisar-se-á, então, se a fotossíntese evidencia corroborativamente o percurso do excesso no nível biológico, conforme as 3 etapas pré-estipuladas (e já aplicadas ao nível astronômico), através do embasamento científico fornecido por instituições do saber em cada respectiva área. Para a primeira etapa de verificação (assegurar que o processo é iniciado por um excesso energético) selecionaram-se informações do serviço de divulgação científica Ask Nature (Pergunte à Natureza) do Biomimicry Institute (Instituto de Biomimética), conforme apresentadas na citação abaixo (traduzida pelo autor deste artigo).

[No processo de fotossíntese] há 2 conjuntos principais de reações: reações de transdução de energia (comumente chamadas de reações luminosas) e reações de fixação de carbono (comumente chamadas de reações escuras). 
Nas reações de transdução de energia, energia solar é convertida em energia química na forma de duas moléculas transportadoras de energia, ATP e NADPH. [...] A energia química dos NADPH e ATP é usada para fornecer potência para os passos subsequentes, as reações de fixação de carbono. (Ask Nature Team, 2018, p. I)

Partindo das informações científicas colhidas nesta citação, é possível responder à primeira etapa de verificação: o processo da fotossíntese é, factualmente, iniciado por um excesso energético, isto, posto que, "energia solar" (justamente o excedente energético liberado pelo sol) "é convertida em energia química" na primeira etapa do processo (reações de transdução de energia) e tal energia química "é usada para fornecer potência para os passos subsequentes" do processo da fotossíntese, logo, é o excedente energético solar, captado pelo ser fotossintetizante, que provoca a inicialização e fornece a energia extra (que não estava no próprio ser, mas foi captada na energia luminosa) para realização de o restante do processo.

Assim, a primeira etapa de verificação concedeu uma resposta positiva à hipótese aqui em desenvolvimento, logo, segue-se para a segunda etapa (certificar que o processo é mediado pela liberação do excedente de energia) e para a terceira etapa (comprovar que o processo acarreta recepção, por outro processo, da respectiva energia liberada), o que pode ser feito pela utilização do embasamento em ciência biológica fornecido pelo Serviço de Extensão da

Universidade do Estado do Michigan (citação traduzida pelo autor deste artigo):

[...] alguns indivíduos perderam o propósito da fotossíntese. Ele não é a produção de oxigênio. A função primaria da fotossíntese é converter energia solar em energia química e então armazená-la para uso futuro. [...] Em essência, plantas verdes pegam carbono, hidrogênio e oxigênio das moléculas de dióxido de carbono e água, e então recombinam eles em uma nova molécula chamada glicose. Isso ocorre na presença da luz do sol, é claro. Energia é armazenada nas ligações da molécula de glicose. [...] quimicamente falando, a entrada da fotossíntese é de 6 carbonos, I2 hidrogênios e 18 oxigênios. A glicose usa 6 carbonos, 12 hidrogênios e 6 oxigênios. Matemática simples nos mostra a sobra de 12 oxigênio, ou 6 moléculas de oxigênio. [...] Interessantemente, e não só coincidentemente, o processo de respiração quebra a molécula de glicose. Respiração ocorre nas células de praticamente todas as coisas vivas. A energia liberada é então usada para todos os tipos de atividade metabólica. A energia é liberada com algum dióxido de carbono [...] O oxigênio é um subproduto da fotossíntese como, correspondentemente, dióxido de carbono é um subproduto da respiração. [...] (COOK, 2013, p. I)

A segunda pôde ser comprovada nesta citação, uma vez que a fotossíntese liberou um excedente de energia (energia química, oxigênio molecular), um "subproduto", como mediação para cumprimento de sua "função primária" (armazenar energia química como 
glicose). A terceira etapa também pôde ser positivamente averiguada, pois, o processo em questão (fotossíntese) entregou a outro processo (respiração) a energia liberada na etapa anterior (oxigênio molecular, energia química).

\section{Conclusões}

A hipótese do Excesso poder ser escolhido como um elemento de coerência entre eventos que não apela a máximos e mínimos absolutos, conforme proposto por Whitehead para a filosofia da ciência, foi corroborada atendendo aos entendimentos conceituais de Excesso, desenvolvidos no tópico 2, e respondendo aos quesitos de teste de embasamento científico, desenvolvidos no tópico 3. É necessário considerar a limitação deste trabalho, pois, dada a brevidade deste artigo, somente duas séries de eventos (processos) puderam ser averiguados na testagem proposta.

\section{Referências bibliográficas}

BAtaille, G. A Parte Maldita, precedida de A noção de Dispêndio. Tradução: GUIMARÃES, J. C. Belo Horizonte: Editora Autentica, 2016.

COOK, B. The Important Role of Photosynthesis. East Lansing: MSU, 2013.

DAWKINS, R. O Gene Egoísta. Tradução: RUBINO, R. São Paulo: Bookman, 2007. GASPAR, A. Física. Vol. Único - I. a edição. São Paulo: Editora Ática, 2005.

HEWITT, P. G. Fundamentos de Física Conceitual. Tradução: RICCI, T. F. Porto Alegre: Bookman, 2009.

Photosynthesis converts solar energy into chemical energy. Missoula: Ask Nature, 2018. Disponível em: https://asknature.org/strategy/photosynthesis-converts-solarenergy-into-chemical-energy/ .

TRUElOVE, E; DEJOIE, J. What Makes The Sun Shine. NASA: StarChild, 1999. Disponível em: https://starchild.gsfc.nasa.gov/docquestions/questionı.html

WhiteHEAD, A. N. O Conceito de Natureza [1920]. Tradução: Júlio B. Fischer. São Paulo: Editora Martins Fontes, 1993. 